\title{
To assess the prevalence of malnutrition among the children of age group of 0 - 5 years in the rural area of Vidarbha region
}

\author{
Amrapali Gajbhiye ${ }^{1, *}$, Gajanan Vellhal ${ }^{2}$, Mary Mathews ${ }^{3}$, Meenakhi Girish ${ }^{4}$ \\ ${ }^{1}$ PhD Scholar, Dept. of Nursing, MGM Institute of Health Sciences, Mumbai, Maharashtra, ${ }^{2}$ Professor and Head, Dept. of \\ Community Medicine, Seth J. S. Medical College, KEM Hospital, Mumbai, Maharashtra, ${ }^{3}$ Professor Cum Principal, MGM \\ College of Nursing, Mumbai, Maharashtra, ${ }^{4}$ Associate Professor, Dept. of Paediatric, NKP Salve Institute of Medical Sciences \\ and Research Centre, Nagpur, Maharashtra, India
}

*Corresponding Author:

Email: wankhede.amrapali@gmail.com

\begin{abstract}
The problems of malnutrition among under-five children can be used to determine the need for nutritional surveillance, nutritional care, or appropriate nutritional intervention programmes in a community. The present study was planned to assess prevalence of malnutrition in children of the age group of 0 to 5 years. A village based study was carried out to assess prevalence of malnutrition among under-five children at the rural area of Katol. Data was collected by interview schedule for collection of socio-demographic and physical examination format for assessing malnutrition status from January 2016 to April 2016 . A child's detailed history, sex and weight were recorded and length/height were measured using standard technique. The height and weight were plotted on WHO centiles curves. The malnutrition was graded according to WHO classification. Data analysis was done by using WHO Anthro and SPSS software. Total study subjects age group 0-5yrs. 310 study subjects were in study group and 320 study subjects in control group. As per WHO classification of protein energy malnutrition, 75/320(23.43\%) from control group and 59/310 (19,03\%) from study group study subjects were in normal range Significantly higher number no children from study group $80.96 \%$ (251/310) showed malnutrition by applying any of the anthropometric parameter than that in control group $76.56 \%$ $(245 / 320)(\chi 2$ - value $=13.43$, $p$-value $=0.0038)$. In conclusion, high percentage of malnutrition was found in under five children in male children.
\end{abstract}

Keywords: Malnutrition, Children, WHO, Rural.

\section{Introduction}

Malnourishment is a serious challenging problem in India. These children are having comparatively higher mortality and morbidity rates. Under-five children's malnourishment is still major developmental challenge. ${ }^{1-3}$ India had enormous economic growth in last 20-30 years despite of this malnutrition is common in both Urban and rural areas. Nevertheless, multiple cases have noticed, so health care sectors and government are taking necessary steps to improve the present condition. Malnutrition is a silent emergency. It's a major part of various cycles that includes poverty and disease. All these factors are interrelated and independent. Socioeconomic and political influence can beat this ferocious cycle for which specific nutritional and health actions are mandatory. Presently in developing countries, health and social consequences affects child growth. The result of this impaired growth during childhood can be classified in terms of morbidity, mortality and psychological and intellectual development. ${ }^{4-7}$ These affects can also be seen in adult life in terms of body size, work, reproductive performances and risk of chronic illness.

The government has envisaged a "multi sectoral approach" and "direct and specific interventions" to address the issue of nutritional problem. In spite of all these attempts, the problem still exists and has not been resolved to the desired level..$^{8-9}$ On this ground it has now become necessary to look into the depth of the problem, by understanding the situation inside the house. Present research study proposes to adopt village based planning strategy with due considerations to community involvement, and participation and to deliver scientifically sound and appropriate need based interventions to address various nutritional problems in rural set up.

\section{Aim and Objective}

1. To assess prevalence of malnutrition in children of age group 0 to 5 years.

\section{Materials and Methods}

The present study adopts an experimental epidemiological study design (Pre and post intervention, with control group) - community trial approach. Study was conducted in Rural field practice area under NKP Salve Medical College, Katol block, Nagpur, among all the children in the age group of 0 to 5 years from the randomly selected PHC (Yenva) and selected 5 villages under Sub-center-(Zilpa, and Mendki) fulfilling inclusion and exclusion criteria.

Sample Size: Study group - 310, Control group - 320 (based on existing data of Sub -centre)

As an intervention, present study proposes to adopt the village based planning strategy (through village empowerment Committee) empowering the community and families to take care of nutritional wellbeing of the children in the age group of $0-5$ years.

Data collection tools appropriately validated and data analysed under the guidance of qualified 
statistician using SPSS (19.00 version) software. The tool was validated by experts from tool validity committee from MGM University. Valuable suggestions were given and necessary correction was made after the consultation with the guide.

Permission was obtained from the medical officers from Yenva PHC. Before doing assessment self introduction and the purpose of the study was mentioned by the investigator. Consent of the samples was taken. Demographic information was completed by the interview method. The protein energy malnutrition assessment of the samples was done by physical assessment. The grading was done according to WHO.

\begin{abstract}
Results
Percentage wise Distribution of under Five Children according to their Demographic Variables (Environmental Conditions and Socio-Economic Status): This section deals with percentage wise distribution of under- five children according to their demographic variables (environmental conditions and socio-economic status). Non-probability convenient samples of 630 subjects were drawn from study population, whom were selected from Katol area. The data obtained from the subjects describe the environmental conditions socioeconomic status is presented in the form of frequency, percentage, their chi-square value and level of significance (Table 1).
\end{abstract}

Table 1: Percentage wise distribution of population according to their environmental conditions $(n=630)$

\begin{tabular}{|c|c|c|c|c|}
\hline \multirow{2}{*}{ Environmental Conditions } & \multicolumn{2}{|c|}{ Study Group $(\mathrm{n}=310)$} & \multicolumn{2}{|c|}{ Control Group $(\mathbf{n}=320)$} \\
\hline & Frequency & $\%$ & Frequency & $\%$ \\
\hline \multicolumn{5}{|l|}{ Type of House } \\
\hline Pacca House & 159 & 51.29 & 157 & 49.06 \\
\hline Kaccha House & 112 & 36.13 & 16 & 5.00 \\
\hline Semi Pacca House & 39 & 12.58 & 147 & 45.94 \\
\hline \multicolumn{5}{|l|}{ Ventilation } \\
\hline Yes & 170 & 54.84 & 182 & 56.88 \\
\hline No & 140 & 45.16 & 138 & 43.13 \\
\hline \multicolumn{5}{|l|}{ Light } \\
\hline Natural & 240 & 77.42 & 65 & 20.31 \\
\hline Artificial & 70 & 22.58 & 255 & 79.69 \\
\hline \multicolumn{5}{|l|}{ Separate Kitchen } \\
\hline Yes & 223 & 71.94 & 230 & 71.88 \\
\hline No & 87 & 28.06 & 90 & 28.13 \\
\hline \multicolumn{5}{|l|}{ Smoke Outlet } \\
\hline Yes & 59 & 19.03 & 79 & 24.69 \\
\hline No & 251 & 80.97 & 241 & 75.31 \\
\hline \multicolumn{5}{|l|}{ Electricity } \\
\hline Yes & 304 & 98.06 & 297 & 92.81 \\
\hline No & 6 & 1.94 & 23 & 7.19 \\
\hline \multicolumn{5}{|l|}{ Type of cooking fuel } \\
\hline Firewood & 129 & 41.61 & 157 & 49.06 \\
\hline Kerosene & 13 & 4.19 & 10 & 3.13 \\
\hline Biogas & 6 & 1.94 & 6 & 1.88 \\
\hline LPG & 162 & 52.26 & 147 & 45.94 \\
\hline \multicolumn{5}{|l|}{ Source of drinking water supply } \\
\hline Sanitary Well & 127 & 40.97 & 89 & 27.81 \\
\hline Bore Well & 27 & 8.71 & 39 & 12.19 \\
\hline Public Tab & 140 & 45.16 & 170 & 53.13 \\
\hline Pond & 2 & 0.65 & 2 & 0.63 \\
\hline Others & 14 & 4.52 & 20 & 6.25 \\
\hline \multicolumn{5}{|l|}{ Water Supply } \\
\hline Continuous & 132 & 42.58 & 168 & 52.50 \\
\hline Intermittent & 178 & 57.42 & 152 & 47.50 \\
\hline \multicolumn{5}{|c|}{ Method of drinking water purification } \\
\hline Strains water by cloth & 220 & 70.97 & 250 & 78.13 \\
\hline Uses Alum & 20 & 6.45 & 26 & 8.13 \\
\hline Water Filter & 12 & 3.87 & 21 & 6.56 \\
\hline Boils Water & 6 & 1.94 & 7 & 2.19 \\
\hline
\end{tabular}




\begin{tabular}{|l|c|c|c|c|}
\hline Electric Purifier & 6 & 1.94 & 5 & 1.56 \\
\hline Does not purify & 46 & 14.84 & 11 & 3.44 \\
\hline Mode of disposal of domestic waste & \multicolumn{5}{|l|}{} \\
\hline Dumping indiscriminately & 22 & 7.10 & 43 & 13.44 \\
\hline Dumping in pit & 43 & 13.87 & 58 & 18.13 \\
\hline Community Dumping & 212 & 68.39 & 213 & 66.56 \\
\hline Manure Pit & 27 & 8.71 & 2 & 0.63 \\
\hline Burning & 6 & 1.94 & 4 & 1.25 \\
\hline Sanitary Latrine & 43 & 13.87 & 231 & 72.19 \\
\hline Present and in use & 201 & 64.84 & 16 & 5.00 \\
\hline Present and not in use & 66 & 21.29 & 73 & 22.81 \\
\hline Absent & \multicolumn{5}{|l}{} \\
\hline Type of salt used & 282 & 90.97 & 271 & 84.69 \\
\hline Powdered Salt & 28 & 9.03 & 49 & 15.31 \\
\hline Crystal Salt
\end{tabular}

Out of 13 environmental conditions 9 conditions i.e. type of house, light, electricity, sources of drinking water supply, water supply, method of drinking water purification, mode of disposal of domestic waste, sanitary latrine and type of salt used were found to comparable. Likewise ventilation, separate kitchen, smoke outlet and type of cooking fuel were not comparable.

Table 2: Socio-economic status wise distribution of malnutrition among study and control subjects

\begin{tabular}{|l|c|c|c|c|}
\hline \multirow{2}{*}{ Kuku swami } & \multicolumn{2}{|c|}{ Study Group(n=310) } & Control Group(n=320) \\
\cline { 2 - 5 } & Frequency & $\mathbf{\%}$ & Frequency & \% \\
\hline Class I(Upper) & 44 & 14.2 & 25 & 7.81 \\
\hline Class II(Upper Middle) & 27 & 8.7 & 46 & 14.38 \\
\hline Class III(Middle) & 84 & 27.1 & 98 & 30.63 \\
\hline Class IV(Lower Middle) & 43 & 13.9 & 53 & 16.56 \\
\hline Class V(Lower) & 112 & 36.1 & 98 & 30.63 \\
\hline Total & 310 & 100 & 320 & 100 \\
\hline$\chi 2$-value & $13.07, \mathrm{p}$-value $=0.019$, Significant, $\mathrm{p}<0.05$ \\
\hline
\end{tabular}

Table 2 shows that majority of the children was belonging to Class III (Middle) and Class V (Lower). For the above table, the calculated chi-square value was greater than tabulated chi-square, thus socio-economic status was found to be significant. Henceforth for both study group and control group, the malnutrition of the children varies according to the socio-economic status.

In maternal care form 21 components were selected and assessed by interview schedule. out of 21 components of maternal care 9 components i.e. ANC registration, number of antenatal check-up, number of time blood pressure checked during last pregnancy, number of abdomen examined during pregnancy, TT injections given during pregnancy, iron supplements given and consumed during pregnancy, delivery conducted and type of delivery were found to be comparable.. Likewise rest of the components were found to be non-significant. These conditions were not comparable.

Simultaneously birth registration for children in the age group of 0-5 years was assessed by using 9 components. Out of 9 components of birth registration of children in the age group of 0 to 5 years 4 components were found to be significant. These conditions were significant because their calculated chisquare value was greater than the tabulated chi-square value at level of significance of 0.05 . Likewise 1 was found to be non-significant. These conditions were nonsignificant because their calculated chi-square value was less than the tabulated chi-square value at level of significance of 0.05 .

Table 3: Type of illnesses (Conditioning influences form no. 4)

\begin{tabular}{|l|c|c|c|c|c|c|}
\hline & \multicolumn{2}{|c|}{ Study Group } & \multicolumn{2}{c|}{ Control Group } & \multirow{2}{*}{ 2-value } & \multirow{2}{*}{ p-value } \\
\hline & Frequency & $\mathbf{\%}$ & Frequency & $\mathbf{\%}$ & & \\
\hline Fever & 28 & 9.03 & 16 & 5.00 & 3.94 & $0.047, \mathrm{~S}$ \\
\hline Acute Respiratory Infection & 22 & 7.09 & 10 & 3.13 & 4.90 & $0.026, \mathrm{~S}$ \\
\hline Worm Infestation & 56 & 18.06 & 35 & 10.93 & 6.47 & $0.011, \mathrm{~S}$ \\
\hline Diarrhoea & 18 & 5.08 & 33 & 10.31 & 4.29 & $0.038, \mathrm{~S}$ \\
\hline
\end{tabular}


For histories of illnesses; all were found to be significant. These conditions were significant because their calculated chi-square value was greater than the tabulated chi-square value at level of significance of 0.05 (Table 3).

Table 4: Immunization and vitamin A prophylaxis

\begin{tabular}{|l|c|c|c|c|c|c|}
\hline & \multicolumn{2}{|c|}{ Study Group } & \multicolumn{2}{c|}{ Control Group } & \multirow{2}{*}{$\boldsymbol{\chi}$ 2-value } & \multirow{2}{*}{ p-value } \\
\hline & Frequency & $\mathbf{\%}$ & Frequency & $\boldsymbol{\%}$ & & \\
\hline Partially Immunized & 58 & 18.71 & 72 & 22.50 & 0.48 & $0.48, \mathrm{NS}$ \\
\hline Fully Immunization & 239 & 77.10 & 238 & 74.38 & 0.24 & $0.62, \mathrm{NS}$ \\
\hline Vitamin A Prophylaxis & 203 & 65.48 & 247 & 77.19 & 3.49 & $0.06, \mathrm{NS}$ \\
\hline Unimmunized & 21 & 6.77 & 3 & 0.94 & 4.68 & $0.030, \mathrm{~S}$ \\
\hline
\end{tabular}

Table 4 shows that out of 4 components of immunization and Vitamin A prophylaxis 1 component was found to be significant. These conditions were significant because their calculated chi-square value was greater than the tabulated chi-square value at level of significance of 0.05 . Likewise 3 were found to be non-significant. These conditions were non- significant because their calculated chi-square value was less than the tabulated chi-square value at level of significance of 0.05 .

Distribution of under-five Children with Regards to their Nutritional Status: This section deals with the assessment of nutritional status of under-five children regarding the parameters of protein energy malnutrition, specific vitamin deficiency, and specific trace elements for new-born and child.

Table 5: Percentage of underweight, stunting and wasting total population (WHO Classification)

\begin{tabular}{|l|c|c|c|c|c|c|}
\hline \multirow{2}{*}{} & \multicolumn{7}{|c|}{ Study group } & \multicolumn{3}{c|}{ Control group } \\
\cline { 2 - 7 } & $\mathbf{M}(\mathbf{1 7 8})$ & $\mathbf{F}(\mathbf{1 3 2})$ & Total(310) & $\mathbf{M}(\mathbf{1 5 8})$ & $\mathbf{F}(\mathbf{1 6 2})$ & Total(320) \\
\hline Normal & $28(15.73 \%)$ & $31(23.48 \%)$ & $59(19.03 \%)$ & $19(12.02 \%)$ & $56(34.56 \%)$ & $75(23.43 \%)$ \\
\hline Underweight & $47(26.40 \%)$ & $30(22.72 \%)$ & $77(24.83 \%)$ & $43(27.21 \%)$ & $35(21.60 \%)$ & $78(24.37 \%)$ \\
\hline Wasting & $30(16.85 \%)$ & $11(8.33 \%)$ & $41(13.22 \%)$ & $45(28.48 \%)$ & $23(14.19 \%)$ & $68(21.25 \%)$ \\
\hline Stunting & $73(41.01 \%)$ & $60(45.45 \%)$ & $133(42.90 \%)$ & $51(32.27 \%)$ & $48(29.62 \%)$ & $99(30.93 \%)$ \\
\hline Total & $178(100 \%)$ & $132(100 \%)$ & $310(100 \%)$ & $158(100 \%)$ & $162(100 \%)$ & $320(100 \%)$ \\
\hline$\chi 2$-value & \multicolumn{7}{|c|}{$13.43, p$-value $=0.0038$, Significant } \\
\hline
\end{tabular}

As per indicators of malnutrition of protein energy malnutrition, 75/320(23.43\%) from control group and $59 / 310(19,03 \%)$ from study group study subjects were in normal range (Table 5). Significantly higher number no children from study group $80.96 \%$ (251/310) showed malnutrition by applying any of the anthropometric parameter than that in control group $84.26 \%(245 / 320)\left(\chi^{2}-\right.$ value $=13.43$, p-value $\left.=0.0038\right)$. In both the group more no of male children were seemed to have malnutrition by applying any one of anthropometric parameter than that in female children from study group (male children 150/178 (84.26\%) female children $101 / 132(76.51 \%)$ as well as in control group (male children 139/158(87.97\%), female children $106 / 162(65.43 \%)$. Majority of children were stunted $133 / 251$ (52.98\%) followed by underweight $139 / 158$ (87.97\%and wasting $41 / 251(16.33 \%)$ in study group as well as in control group stunted 199/245(40.40\%), underweight 78/245(31.83\%), wasted 68/245(27.75\%).

\section{Discussion}

Protein calorie malnutrition is one of the common nutritional diseases in developing countries. In comparison to females, males are more affected with malnutrition. In study group out of 251, 150 males and
101 females were malnourished. Subsequently in control group, out of 245 children 139 males and 106 females were malnourished. The proportion of malnourished was higher among under five children. Similar results were observed by Srivastava RK et al ${ }^{10}$ improper weaning- frequent and recurrent infection makes this group vulnerable.

As per indicators of malnutrition of protein energy malnutrition, 75/320(23.43\%) from control group and $59 / 310(19.03 \%)$ from study group study subjects were in normal range. Significantly higher number no children from study group $80.96 \%$ (251/310) showed malnutrition by applying any of the anthropometric parameter than that in control group $84.26 \%$ (245/320). In both the group more no of male children were seemed to have malnutrition by applying any one of anthropometric parameter than that in female children from study group (male children 150/178 (84.26\%) and female children 101/132(76.51\%) as well as in control group (male children 139/158(87.97\%), female children 106/162(65.43\%). Similar community-based crosssectional survey was conducted by Amareon D et al, ${ }^{11}$ 342 study participants. Weight and height were measured using calibrated instruments. The data were entered into Epi-Data version 3.1 software and 
calculated using SPSS version 20.0 statistical software and/or World Health Organization Anthro software with aid of Stat/Transfer. Overall prevalence of undernutrition was $35.5 \%$, of which 85 (24.9\%), 38 $(11.1 \%)$, and $49(14.3 \%)$ were stunting, wasting, and underweight, respectively. Male children were more affected in both severe and moderate nutritional problems compared to female children.

Majority of children were stunted 133/251 (52.98\%) followed by underweight $139 / 158(87.97 \%$ and wasting $41 / 251(16.33 \%)$ in study group as well as in control group stunted 199/245(40.40\%), underweight 78/245(31.83\%), wasted 68/245(27.75\%). Similar results were observed by Sahu $\mathrm{SK}^{12}$ who has collected data from Google search, Medline, and others. The information retrieved was reviewed and analyzed for discrepancies. Existing evidence shows that the prevalence of under-nutrition among under-five children was high and varied widely (under-weight: 39$75 \%$, stunting: $15.4-74 \%$, wasting: $10.6-42.3 \%$ ) depending on the assessment methodology adopted.

\section{Recommendation}

Reduction of malnutrition in $0-5$ age group can been sure by availability of supplementary feed. Healthcare providers to focus on health education among parents, especially the mothers on the exact nutritional requirements in terms of quality and quantity of the child at specific age groups.

\section{Conclusion}

Majority of under five children were malnourished in study group were $80.96 \%$ and in control group were $76.56 \%$ Here malnutrition was more common in males than females.

\section{References}

1. Basal RD, Mehra M. Malnutrition: A silent emergency. Indian J Public Health. 1991;43(1):1-2.

2. Park K. Health care of the community. In: Park K, editor. Park's Textbook of Preventive and Social Medicine. $18^{\text {th }}$ ed. Jabalpur: Bhanot Publications; 2005. p. 405.

3. Bloss E, Wainaina F, Bailey RC. Prevalence and predictors of underweight, stunting, and wasting among children aged 5 and under in Western Kenya. Journal of Tropical Pediatrics. 2004;50(5):260-270.

4. Agarwal V. Integrated management of neonatal and childhood illness: Continuing medical education Module Public Health Department. 2005:6-8.

5. Park K. Health care of the community. In: Park K, editor. Park's Textbook of Preventive and Social Medicine. $18^{\text {th }}$ ed. Jabalpur: Bhanot Publications; 2005. p. 406.

6. Progress for children A report card on Nutrition UNICEF: Times of India, May 2006.

7. Kumar P. Social classification need for constant upgrading. Indian Journal of Community Med. 1993:18(2):60-61.

8. Software for assessing growth and development of the world's children Geneva WHO, 2010. Available from: http://www.who.int/childgrowth/software/en/.

9. Water low IC, Buzina R, Keller W, Lane IM, Nichaman MZ, Tanner IM. The presentation and use of height and weight data for comparing the nutritional status of groups of children under the age of 10 years. Bull World Health Organ. 1977;55:489-498.

10. Srivastava RK, Anwar F, Gupta MK, Prabha C. Malnutrition among rural Indian children: An assessment using web of indices. International Journal of Public Health and Epidemiology. 2013;2(4):78-84.

11. Amare D, Negesse A, Tsegaye B, Assefa B, Ayenie B. Prevalence of undernutrition and its associated factors among children below five years of age in Bure Town, West Gojjam Zone, Amhara National Regional State, Northwest Ethiopia. Advances in Public Health 2016; Article ID 7145708: 1-8. Available on: http://dx.doi.org/10.1155/2016/7145708.

12. Sahu SK, Kumar SG, Bhat BV, Premarajan KC, Sarkar S, Roy G, et al. Malnutrition among under-five children in India and strategies for control. J Nat Sci Biol Med. 2015;6(1):18-23. 